\title{
Uma linha de Pesquisas sobre Políticas de Drogas no Ipea ${ }^{1}$
}

Milena Karla Soares²

Maria Paula Santos 3

\section{INTRODUÇÃO}

A linha de pesquisas sobre políticas de drogas,${ }^{4}$ hoje assentada na Diretoria de Estudos e Políticas do Estado, das Instituições e da Democracia (Diest), se estabeleceu poucos anos depois da criação da diretoria. Seus primeiros projetos tiveram início em 2014 e se desenvolveram em parceria com a Secretaria Nacional de Políticas sobre Drogas (Senad), do Ministério da Justiça (MJ), quais sejam: um levantamento nacional sobre comunidades terapêuticas (CTs) - instituiçóes da sociedade civil que se dedicam ao cuidado de pessoas com problemas decorrentes do uso de álcool e outras drogas; e o Plano de Monitoramento dos Efeitos da Nova Política Uruguaia de Regulaçáo do Mercado de Cannabis sobre a Zona de Fronteira, projeto que envolvia um conjunto de pesquisas a serem realizadas por instituiçóes brasileiras e uruguaias.

O MJ detinha então competências tanto para atividades de combate ao tráfico ilícito de drogas, quanto de prevenção do uso indevido destas substâncias e de atenção e reinserção social de pessoas consideradas dependentes de drogas. ${ }^{5}$ Os primeiros projetos refletiam temas emergentes (e polêmicos) em cada um destes eixos e descortinaram uma série de questóes relevantes que tinha sido pouco tratada até então pelo Ipea, especialmente: a compreensão sobre as perniciosas consequências sociais das políticas proibicionistas; a questionável racionalidade científica do regime internacional de drogas; bem como a tendência de esvaziamento deste regime, a partir da adoçáo de políticas nacionais alternativas à proibição.

As políticas brasileiras de drogas têm sido historicamente alinhadas ao paradigma internacional da chamada guerra às drogas. A Lei de Drogas hoje vigente (Lei oㅜ 11.343/2006), assim como as normas que a precederam, têm produzido consequências sociais dramáticas para o país, entre as quais: encarceramento em massa, escalada da letalidade policial, além de extensiva vitimização de amplos contingentes da população, moradores das periferias das grandes cidades. Em princípio, essa lei visava trazer alguma moderação ao paradigma proibicionista, ao derrogar a pena de prisão para usuários de drogas e deslocá-lo para o sistema de saúde, a fim de garantir seu tratamento e sua reinserção social. Porém, ao mesmo tempo aumentou-se o tempo de encarceramento para os delitos relacionado ao tráfico de drogas, sem que fossem definidos parâmetros objetivos para a distinção entre os delitos de uso e tráfico de drogas. Tal distinção passaria a ser feita pelo juiz do caso, que

1. DOl: http://dx.doi.org/10.38116/bapi29art13

2. Técnica de desenvolvimento da administração na Diretoria de Estudos e Políticas do Estado, das Instituiç̧ões e da Democracia (Diest) do Ipea. 3. Técnica de planejamento e pesquisa na Diest//pea.

4. Até o momento, a linha de pesquisas na Diest tem tratado apenas das políticas de drogas consideradas ilíitas, ou seja, cujo uso recreativo é proibido pelos regramentos nacionais e internacionais, como maconha (cannabis), cocaína, crack, dietilamida do ácido lisérgico (LSD), heroína, entre outras. Entretanto, não passa despercebido às autoras que existem drogas líititas, a exemplo de álcool e tabaco, cujas políticas também podem vir a ser objeto de estudos no âmbito da linha de pesquisa.

5. A partir de 2019, o Ministério da Justiça deixou de ter competência nessas últimas, que foram incorporadas às responsabilidades do Ministério da Cidadania. 
deveria considerar, entre outras coisas, "as circunstâncias sociais e pessoais, bem como a conduta e os antecedentes do agente” (Brasil, 2006). O resultado prático dessa determinação foi o enquadramento mais frequente de usuários de drogas como traficantes, pela justiça de primeiro grau, e um aumento exponencial do encarceramento por tráfico de drogas, nos anos que se seguiram à promulgação da lei. ${ }^{6}$ A despenalização do crime de posse para uso, portanto, acabou tendo um efeito contrário ao esperado. Figuram também na conta desta guerra uma série de obstáculos à efetivação do cuidado a usuários dessas substâncias, bem como ao desenvolvimento de pesquisas dedicadas à utilização farmacológica de algumas delas no tratamento de diversos agravos à saúde. ${ }^{7}$

A regulação do que hoje chamamos drogas remonta ao início do século XX, quando celebraram-se os primeiros tratados internacionais sobre o assunto, ${ }^{8}$ estabelecendo diretrizes de repressão ao uso não médico de um conjunto de substâncias. Embora a distinção entre drogas lícitas e ilícitas não leve em conta critérios científicos relativos aos danos potenciais de cada substância, e esteja associada a históricos preconceitos sociais e raciais, ${ }^{9}$ convençôes internacionais têm ditado os contornos das políticas domésticas de drogas mundo afora, promovendo certo isomorfismo entre elas e limitando a discricionariedade dos países nesse campo.

Atualmente, em 2020, esse regime internacional se encontra em processo de esvaziamento, como atestam as conversações mantidas na sessão especial da Assembleia-Geral das Nações Unidas sobre o Problema Mundial das Drogas, realizada em 2016, ${ }^{10}$ bem como as iniciativas recentes de diversos países, em favor de novos marcos regulatórios - como Portugal, Uruguai, Canadá e vários estados-membros dos Estados Unidos (Paiva, 2018). Ainda que alvissareiro, esse processo impóe a países como o Brasil - profundamente implicado no comércio internacional de drogas - a necessidade de se engajarem na construção de um novo pacto internacional, para que não fiquem, mais uma vez, a reboque de normas ditadas externamente, tendo que lidar com suas consequências. Náo por acaso, os países que mais sofrem com as perniciosas consequências da guerra às drogas são também aqueles com menor capacidade de influenciar os acordos internacionais sobre a matéria. A condição periférica desses países, desde a origem do regime internacional, persiste até os dias de hoje, impondo a necessidade de coalizóes entre naçóes, para que o tema entre na agenda.

Atenta a essas questóes, a Diest tem realizado pesquisas, estudos e publicaçóes nesse tema, abrangendo dois eixos das políticas de drogas: atenção e reinserção social de usuários e dependentes; e controle da oferta de drogas. Neste texto, apresentamos tais projetos, seus produtos e sua repercussão no debate público, bem como perspectivas para essa linha de pesquisa nos próximos anos. Na seção 2, descrevemos os projetos relativos ao primeiro eixo e, na seção 3, as pesquisas que tratam de temas referidos ao segundo. $\mathrm{O}$ artigo se conclui com nossas consideraçóes finais, em que apontamos alguns desafios para a política brasileira de drogas e uma agenda de pesquisas futuras para o Ipea.

6. Mais informações em IBCCRIM (2016); Jesus et al. (2011); Haber e Maciel (2018); Machado et al. (2019); e Garau e Costa (2020).

7. Disponível em: <https://www.ipea.gov.br/portal/index.php?option=com_content\&view=article\&id=34474\&ltemid=6>.

8. A Primeira Convenção Internacional do Ópio, realizada em 1912, deu início ao regime internacional de controle de drogas (McAllister, 2012; Rodrigues; 2008). Antes, existiram alguns regramentos nacionais e locais sobre o tema, mas sem o alcance e o escopo instituídos dos pelo regime internacional (Bueno 2005; Lima 2009; França, 2015).

9. Uma discussão sobre a base científica do regime internacional de controle de drogas está disponível em Courtwright (2012); Mills (2012); e Thoumi (2016).

10. Disponível em: <https://www.unodc.org/ungass2016/index.html>. Essa edição da UNGASS colocou as bases do regime internacional de controle de drogas em questão (Paiva, 2018). 


\section{CUIDADO AOS USUÁRIOS DE DROGAS}

O primeiro projeto da Diest relativo às políticas sobre drogas foi uma pesquisa, solicitada pela Senad, sobre as CTs atuantes no país, que visava contribuir para o monitoramento e a avaliação do financiamento federal a essas entidades, iniciado a partir de 2011, por determinaçáo do plano Crack, épossivel vencer, instituído pelo Decreto no 7.179, de 20 de maio de 2010 e implementado por aquela secretaria. Essa investigação reuniu informaçóes quantitativas e qualitativas sobre as CTs, abrangendo desde suas condições físicas de acolhimento até suas práticas assistenciais. Iniciado em 2015, esse trabalho rendeu, além de relatórios entregues à Senad em 2016, uma Nota Técnica, publicada pelo Ipea (Santos, 2017) e um livro composto por dez artigos escritos por diferentes pesquisadores que atuaram tanto na produção, quanto na análise das informaçóes levantadas (Santos, 2018). Estes produtos foram apresentados e discutidos em congressos e reuniōes científicas diversos ${ }^{11} \mathrm{e}$ tiveram repercussóes na imprensa, assim como entre as entidades de representação das próprias CTs (Correia e Fonseca, 2020; Machado e Magenta, 2019; Formenti, 2019; FEBRACT, 2017).

Ao longo desta pesquisa, ficou evidente que o tema das CTs inscrevia-se num debate mais amplo que, embora antigo, ganhara renovado vigor, pelo menos desde que o governo federal passou a financiar estas entidades, em 2011. No centro desse debate está a questão das internaçóes, por vezes forçadas, de usuários de drogas em instituiçóes de tratamento fechadas; as implicaçóes dessa prática para a garantia dos direitos fundamentais e humanos dessas pessoas; e a pertinência do financiamento público desse tipo de instituição. Aplicado desde o século XIX a indivíduos com sofrimento mental de todo tipo, esse modelo assistencial, derivado de representaçóes sobre supostas irracionalidade e periculosidade de loucos e toxicômanos, tornar-se ia objeto de extensa crítica, após a Segunda Grande Guerra, quando se renovaram as preocupaçóes com os direitos humanos. Por desconsiderar o direito de escolha daqueles que pretendia tratar e, muitas vezes, atentar contra sua integridade física, a contestação ao antigo modelo psiquiátrico manicomial traria novos ingredientes aos debates sobre cidadania e democracia, e daria ensejo a uma onda de reformas nas políticas de saúde mental em várias partes do mundo (Amarante, 2002).

O Brasil instituiria sua própria reforma psiquiátrica por meio da Lei no 10.216/2001, que restringiu as internaçóes a casos em que "os recursos extra-hospitalares se mostrarem insuficientes" (Brasil, 2001), e passou a oferecer atenção psicossocial em serviços de base comunitária, preservando-se a liberdade dos assistidos. No caso específico das pessoas com problemas decorrentes do uso de álcool e outras drogas, o Ministério da Saúde recomendaria ainda que a abstinência não fosse objetivo único, nem prioritário das intervençôes, e que os serviços deveriam guiar-se pela lógica da redução de danos (Brasil, 2003; Santos e Pires, 2020a; 2020b).

Em face destas diretrizes, a decisão do governo federal de financiar CTs em todo o país deflagraria uma intensa controvérsia, envolvendo atores da sociedade e do próprio Estado. De um lado, algumas instituições - como o Conselho Federal de Psicologia (CFP), a Coordenação de Saúde Mental do Ministério da Saúde (CSM/MS), setores do Ministério Público, entre outras sustentavam que o modelo das $\mathrm{CT}$ s, baseado em internaçóes e voltado precipuamente à promoção da abstinência, contrariaria a Lei no 10.216/2001 e a própria política do Ministério da Saúde. De outro,

11. Resultados dessa pesquisa foram apresentados no 3o Fórum de Direitos Humanos e Saúde Mental, da Associação Brasileira de Saúde Mental (ABRASME), em 2017; no 6e no 70 Congressos Internacionais da Associação Brasileira Multidisciplinar de Estudos sobre Drogas (ABRAMD), de 2017 e 2019, respectivamente; e em três encontros anuais da Associação Nacional de Pós-Graduação e Pesquisa em Ciências Sociais (ANPOCS): 2017, 2018 e 2019. 
representantes das CTs, predominantemente grupos religiosos, além de alguns setores médicos e do sistema de Justiça, entendiam que o tratamento disciplinar das CTs seria o mais adequado à promoção de uma ampla reforma subjetiva e moral dos usuários de substâncias psicoativas. Esse embate se intensificaria quando o CFP, junto ao Ministério Público Federal e ao Mecanismo Nacional de Prevenção a Tortura, do Ministério da Justiça, divulgou um relatório de inspeção, feito em 68 CTs, de 25 estados, em que caracterizaram as disciplinas das CTs como violaçóes de direitos (CFP, 2011). O grupo reivindicava ainda a premissa constitucional do Estado laico para questionar o financiamento das CTs pelo governo.

Essa controvérsia indicou que instaurara-se um conflito político no país que, para além de modelos clínicos ou jurídicos sobre o uso de certas substâncias, referia-se à gestão dos indesejáveis na sociedade brasileira. Para melhor compreender essa problemática, pareceu-nos, então, apropriado conhecer o modelo de cuidado a usuários de álcool e outras drogas (UAD), implementado pelo Ministério da Saúde, que se propunha, alternativamente, a promover o resgate dos direitos de cidadania dessas pessoas, tal como é apresentado em Brasil (2003).

A ideia de pesquisar os serviços de atenção a UAD propostos pelo Ministério da Saúde acabou por interessar também à linha de pesquisas sobre implementação de políticas públicas da própria Diest, o que nos levou a deslanchar, em conjunto, o projeto Metodologias de Cuidado a Pessoas que Fazem Usos Problemáticos de Drogas, em 2018. Esse projeto pretendia realizar pesquisas qualitativas sobre os serviços mencionados, em diferentes cidades brasileiras, que permitissem verificar: i) em que medida as inovaçóes introduzidas pelo modelo do Ministério da Saúde haviam sido efetivamente incorporadas pelos profissionais que atuam na linha de frente dos cuidados; e ii) como se dá a convivência entre os diferentes modelos referidos, no âmbito das redes locais de atenção à saúde.

Tendo concluído as pesquisas no Distrito Federal e na cidade do Rio de Janeiro, nossos primeiros achados indicam que tanto a incorporação do modelo do Ministério da Saúde pelos profissionais que atuam nos serviços de base comunitária, quanto a convivência entre estes e as CTs são, em grande medida, determinados pela intensidade da formação obtida pelos profissionais dos referidos serviços, acerca dos princípios e diretrizes da reforma psiquiátrica, e de seus pressupostos epistemológicos e éticos. ${ }^{12}$

Essa parceria renderia ainda um projeto de pesquisa, realizado no âmbito da cooperação entre o Ipea e a Comissão Econômica para América Latina e Caribe (CEPAL), sobre políticas e programas de assistência a UAD em alguns países da América Latina, a saber: Argentina, Brasil, Colômbia, México e Uruguai. Este projeto resultou na publicação de um livro, com artigos de pesquisadores destes países, além de técnicos do Ipea (Pires e Santos, 2021).

Desde 2019, em virtude do rearranjo institucional das competências em políticas de drogas, as atribuiçóes relacionadas aos cuidados a usuários de drogas foram incorporadas pelo Ministério da Cidadania, mais especificamente pela Secretaria Nacional de Cuidados e Prevenção às Drogas (Senapred), passando a Senad a concentrar esforços no combate ao tráfico de drogas, além a gestão da Fundação Nacional Antidrogas (FUNAD).

12. Essas pesquisas tiveram como primeiros produtos dois relatórios de pesquisa e diversos artigos submetidos à publicação, tanto no Ipea como em outras revistas acadêmicas, como Santos e Pires (2020a; 2020b) e Pires e Santos (no prelo). A expansão das pesquisas para as cidades de Recife e Porto Alegre, conforme inicialmente previsto, está por ora suspensa, em função das circunstâncias da pandemia de Covid-19. 


\section{O CONTROLE DA OFERTA DE DROGAS: MARCOS REGULATÓRIOS E A ATUAÇÃO DO SISTEMA DE JUSTIÇA}

O projeto Monitoramento dos Efeitos da Nova Política Uruguaia de Regulação do Mercado de Cannabis sobre a Zona de Fronteira ${ }^{13}$ foi a primeira atividade da linha de pesquisa sobre drogas, no âmbito do tema da regulação dessas substâncias. O Uruguai foi o primeiro país a regular toda a cadeia de produção, distribuição e consumo de cannabis, e a implementar um modelo de regulação alternativo à proibição total do uso dessa planta. Atentos à significância dessa inovação para o cenário mundial e, em especial, para os países vizinhos ao Brasil, pesquisadores da Diest prontificaram-se a participar do comitê científico assessor responsável pelo acompanhamento da implementação da política uruguaia. ${ }^{14}$

O plano de monitoramento previa a realização de um conjunto de pesquisas por diferentes instituições: além do Ipea, participaram também desse esforço a Universidade Federal de Pelotas (UFPEL) e a Universidad de la Republica (UDELAR), do Uruguai. Ao Ipea, coube conduzir pesquisas sobre a atuação dos sistemas de justiça e segurança pública nos municípios brasileiros da fronteira com o Uruguai, contemplando uma pesquisa de percepção das autoridades de segurança e justiça e uma pesquisa de vitimização e percepção social em políticas sobre drogas na zona de fronteira (Cunha et al., 2017; 2019; Cunha, Pessoa e Soares, 2017; Pessoa e Cunha, 2018). Ainda do lado brasileiro da fronteira, a UFPEL produziu estudos sobre práticas de consumo na mesma região e seus impactos na saúde da população local (Franchini et al., 2017). A UDELAR coordenou estudos semelhantes do lado uruguaio da fronteira (Rossal, Curbelo e Martinez, 2017; Scuro, 2017). Além de relatórios de pesquisa e artigos, essas pesquisas foram apresentadas no Seminário Internacional de Monitoramento e Avaliação da Nova Política Uruguaia de Regulação do Mercado de Cannabis sobre a Zona de Fronteira, em novembro de 2016, ${ }^{15}$ e no 6o Congresso Internacional da Associação Brasileira Multidisciplinar de Estudos sobre Drogas (ABRAMD), em 2017, no qual ganhou prêmio.

Esse projeto ensejou importantes reflexôes sobre o funcionamento de um modelo de regulação alternativo à proibição, suas possibilidades e seus limites, chamando atenção para tensóes e desafios de implementação que surgem no encontro de modelos regulatórios distintos, especialmente em zonas de fronteira permeáveis, como é o caso de Brasil-Uruguai (Cunha, Pessoa e Soares, 2017; Rossal, Curbelo e Martinez, 2017). Atualmente, estão em curso dois projetos relacionados ao controle da oferta de drogas, desenvolvidos a partir de demandas da Senad. O primeiro refere-se ao processamento criminal por tráfico de drogas e consiste em levantamento nacional sobre o perfil das pessoas processadas e a produção de provas nos julgamentos de primeira instância. $\mathrm{O}$ segundo baseia-se em avaliação da aplicação dos recursos orçamentários federais e estaduais relacionados às políticas de drogas no ano de 2019. Estes projetos inserem-se no contexto de recentes alteraçóes na Lei de Drogas, que perpetuam o paradigma repressivo de guerra às drogas ao conferir maior celeridade

13. Plano aprovado no Encontro Binacional Brasil-Uruguai sobre Políticas de Drogas na Fronteira, realizado em Rivera, em 16 de dezembro de 2014.

14. 0 Ipea foi então representado pelo técnico Alexandre dos Santos Cunha.

15. Disponivel em: <https://www.ipea.gov.br/portal/index.php?option=com_content\&view=article\&id=28912:ipea-avalia-efeitos-da-regulacaodo-mercado-de-cannabis-no-uruguai\&catid=8:diest\&directory $=1>$. 
ao processo de perdimento de bens procedentes do tráfico de drogas em favor do FUNAD, ${ }^{16}$ bem como legitimar provas relacionadas à venda de drogas a agente policial disfarçado. ${ }^{17}$

Além dos projetos mencionados, a linha de pesquisas sobre políticas de drogas organizou um número especial do Boletim de Análise Político-Institucional, ${ }^{18} \mathrm{com}$ artigos de estudiosos das diversas áreas associadas ao tema - medicina, psicologia, direito e ciências sociais. Ademais, elaborou artigo de análise do processo recente de regulação da cannabis medicinal no Brasil, pela Agência Nacional de Vigilância Sanitária (ANVISA), a ser publicado também em edição especial deste Boletim, sobre o uso de evidências em políticas públicas, pela administração federal (Soares, 2020). O texto proporciona uma reflexão sobre como a proibição dos usos não médicos de uma substância, e sua constituição como tabu, impóe obstáculos à pesquisa, ao desenvolvimento e ao acesso a medicamentos.

\section{CONSIDERAÇÕES FINAIS}

As políticas de drogas encontram-se no vértice de um conjunto de temas e de políticas públicas que têm sido objeto de análise e acompanhamento pelo Ipea há muitos anos, como segurança pública, saúde, assistência social e direitos humanos. A despeito disso, até seis anos atrás o tema não havia recebido atenção mais sistemática na casa. Contudo, sua emergência como linha de pesquisa, na Diest, revelou um conjunto de questóes incontornáveis, não só para aquelas mesmas políticas, como também para o Estado brasileiro, em suas relaçóes com a sociedade, com outros Estados nacionais e com as arenas internacionais de concertação. Ademais, as inúmeras críticas feitas aos efeitos sociais deletérios do regime proibicionista não têm sido capazes de impulsionar mudanças nas políticas públicas do setor. Ao contrário, como foi dito na seção anterior, a Lei de Drogas sofreu alterações em 2019 que fortaleceram a abordagem punitivista, passando ao largo das reflexóes trazidas a este artigo.

A consolidação dessa linha de pesquisas poderá viabilizar não só o aprofundamento da reflexão sobre os temas em torno dos quais a diretoria já vem se concentrando, como também a abertura de novas frentes de investigação, que se dediquem, por exemplo, a propor políticas e programas mais efetivos de prevenção do uso problemático de drogas; a conhecer os efeitos das diferentes experiências regulatórias do mercado de drogas, que emergem mundo afora; ou ainda a refletir sobre os interesses brasileiros na construção de um novo regime internacional sobre drogas.

\section{REFERÊNCIAS}

ADIALA, J.C. Drogas, medicina e civilização na Primeira República. 2011. Tese (Doutorado) Fundação Oswaldo Cruz, Rio de Janeiro, 2011.

AMARANTE, P. Psiquiatria social e reforma psiquiátrica. Rio de Janeiro: Fiocruz, 2002.

16. A Medida Provisória no 885, de 17 de junho de 2019 (convertida na Lei no 13.886/2019) introduziu alterações na Lei de Drogas (Lei no 11.343/2006), possibilitando que o juiz decrete o perdimento de bens presumidos ilícitos a partir da comparação do patrimônio do réu e seus rendimentos lícitos comprovados.

17. A Lei no 13.964/2019 alterou 0 art. 33 da Lei de Drogas para incluir as condutas de quem "vende ou entrega drogas ou matéria-prima, insumo ou produto químico destinado à preparação de drogas, sem autorização ou em desacordo com a determinação legal ou regulamentar, a agente policial disfarçado, quando presentes elementos probatórios razoáveis de conduta criminal preexistente" (Brasil, 2019b, art. 33, § 1ㅇ, IV). 18. Disponivel em: <https://www.ipea.gov.br/portal/index.php?option=com_content\&view=article\&id=34474\&ltemid=6> . 
BRASIL Lei no 10.216 , de 6 de abril de 2001. Dispõe sobre a proteção e os direitos das pessoas portadoras de transtornos mentais e redireciona o modelo assistencial em saúde mental. Diário Oficial da Uniáo, Brasília, 9 abr. 2001. Disponível em: <http://www.planalto.gov.br/ccivil_03/ LEIS/LEIS_2001/L10216.htm>.

- Ministério da Saúde. A política do Ministério da Saúde para a atençáo integral a usuários de álcool e outras drogas. Brasília: MS, 2003. Disponível em: <http://bvsms.saude.gov.br/bvs/ publicacoes/pns_alcool_drogas.pdf>.

. Lei no 11.343, de 23 de agosto de 2006. Institui o Sistema Nacional de Políticas Públicas sobre Drogas - Sisnad; prescreve medidas para prevenção do uso indevido, atenção e reinserção social de usuários e depelndentes de drogas; estabelece normas para repressão à produção não autorizada e ao tráfico ilícito de drogas; define crimes e dá outras providências. Diário Oficial da União, Brasília, 24 ago. 2006.

. Lei $\mathrm{n}^{\circ} 13.886$ de 17 de outubro de 2019 . Altera as Leis $\mathrm{n}^{\text {os }} 7.560$, de 19 de dezembro de 1986, 10.826, de 22 de dezembro de 2003, 11.343, de 23 de agosto de 2006, 9.503, de 23 de setembro de 1997 (Código de Trânsito Brasileiro), 8.745, de 9 de dezembro de 1993, e 13.756, de 12 de dezembro de 2018, para acelerar a destinaçáo de bens apreendidos ou sequestrados que tenham vinculação com o tráfico ilícito de drogas. Diário Oficial da Uniáo, Brasília, 18 out. 2019a. Disponível em: <http:/www.planalto.gov.br/ccivil_03/_Ato2019-2022/2019/Lei/L13886.htm>.

Lei no 13.964 de 24 de dezembro de 2019. Aperfeiçoa a legislação penal e processual penal. Diário Oficial da Uniáo, Brasília, 19 dez. 2019b. Disponível em: <http:/www.planalto. gov.br/ccivil_03/_Ato2019-2022/2019/Lei/L13964.htm\#: - :text=91\%2DA.,com\%20o\%20seu\%20 rendimento $\% 201 \% \mathrm{C} 3 \% \mathrm{AD}$ cito>.

BUENO, E. À sua saúde: a vigilância sanitária na história do Brasil, Brasília: MS, 2005.

CFP - CONSELHO FEDERAL DE PSICOLOGIA. Relatório da 4a Inspeçáo Nacional de Direitos Humanos: locais de internação para usuários de drogas. Brasília: CFP, 2011. Disponível em: <https://site.cfp.org.br/publicacao/relatorio-da-4a-inspecao-nacional-dedireitos-humanos-locaisde-internacao-para-usuarios-de-drogas-2a-edicao/>.

CORREIA, M.; FONSECA, B. Entidades cristãs receberam quase 70\% da verba federal para comunidades terapêuticas no primeiro ano de governo Bolsonaro. Agência Pública, 27 de julho de 2020. Disponível em: <https://apublica.org/2020/07/entidades-cristas-receberam-quase-70-daverba-federal-para-comunidades-terapeuticas-no-primeiro-ano-de-governo-bolsonaro/>.

COURTWRIGHT, D.T. A short history of drug policy or Why we make war on some drugs but not on others. LSE Ideas: governing the global drug war, London, p. 17-24, Oct. 2012. (Special Report, SR014).

CUNHA, A. S. et al. Monitoramento dos efeitos da nova política uruguaia de regulaçáo do mercado de cannabis sobre a zona de fronteira: vitimização e percepção social em políticas sobre drogas na fronteira brasileira com o Uruguai. Brasília: Ipea, 2017. (Relatório de Pesquisa).

CUNHA, A. S. et al. Monitoramento dos efeitos da nova política uruguaia de regulaçáo do mercado de cannabis sobre a zona de fronteira: vitimização e percepção social em políticas sobre drogas na fronteira brasileira com o Uruguai - segunda rodada Brasília: Ipea, 2019. (Relatório de Pesquisa). 
CUNHA, A. S.; PESSOA, O. A. G.; SOARES, M. K. Monitoramento dos efeitos da nova política uruguaia de regulaçáo do mercado de cannabis sobre a zona de fronteira: percepção das autoridades de segurança e dos atores do sistema de justiça. Brasília: Ipea, 2017. (Relatório de Pesquisa).

FÁBIO, A. C. Comunidades terapêuticas mantêm internaçôes durante a pandemia e veem número de contaminados aumentar. Agência Pública, 25 de junho de 2020. Disponível em: <https://apublica. org/2020/06/comunidades-terapeuticas-mantem-internacoes-durante-a-pandemia-e-veem-numerode-contaminados-aumentar/>.

FEBRACT - FEDERAÇÃO BRASILEIRA DE COMUNIDADES TERAPÊUTICAS. Pronunciamento sobre a nota técnica do Ipea. FEBRACT, 31 maio 2017. Disponível em: <https://febract.org.br/ portal/pronunciamento-sobre-a-nota-tecnica-do-ipea/>.

FORMENTI, L. Com foco em abstinência, governo quer financiar 2020 mil vagas em comunidades terapêuticas. O Estado de São Paulo, 16 maio 2019. Disponível em: <https://brasil.estadao. com.br/noticias/geral,com-foco-em-abstinencia-governo-quer-financiar-20-mil-comunidadesterapeuticas, $70002830714>$.

FRANÇA, J. M. C. História da maconha no Brasil. São Paulo: Três Estrelas, 2015.

FRANCHINI, B. et al. O consumo de drogas e a saúde pública na zona de fronteira entre Brasil e Uruguai: resultados qualitativos. Brasília: Ipea, 2017. (Relatório de Pesquisa).

GARAU, M.G.R.; COSTA, P. A. B. "É posse pra uso ou é tráfico”? Um estudo sobre os critérios utilizados pelos policiais no registro da ocorrência nos crimes da Lei 11.343/06. Revista Brasileira de Sociologia do Direito, v. 7, n. 1, jan./abr. 2020.

HABER, C.D.; MACIEL, N.C.A. As sentenças judiciais por tráfico de drogas na cidade e Região Metropolitana do Rio de Janeiro. Cadernos de Segurança Pública, n. 10, ano 10, 2018.

IBCCRIM - INSTITUTO BRASILEIRO DE CIENNCAS CRIMINAIS. Editorial: UNGASS 2016 e os 10 anos da Lei 11.343/2006. Boletim IBCCRIM, v. 286, 2016.

IPEA - INSTITUTO DE PESQUISA ECONÔMICA APLICADA. Boletim de Análise Político-Institucional, n. 18, 2018.

JESUS, M.G.M. et al. Prisão provisória e Lei de Drogas: um estudo sobre os flagrantes de tráfico de drogas na cidade de São Paulo. São Paulo: Núcleo de Estudos sobre Violência, 2011. (Relatório de Pesquisa). Disponível em: <https://nev.prp.usp.br/publicacao/priso-provisria-e-lei-de-drogas/>.

LIMA, R. C. C. Uma história das drogas e seu proibicionismo transnacional: relaçôes Brasil-Estados Unidos e os organismos internacionais. 2009. Tese (Doutorado) - Universidade Federal do Rio de Janeiro, Rio de Janeiro, 2009.

MACHADO, M.R. et al. Prender a qualquer custo: o tráfico de drogas e a pena de prisão na fundamentação judicial brasileira. Journal of Illicit Economies and Development, n. 1, v. 2, 2019. DOI: <https://doi. org/10.31389/jied.37>.

MACHADO, L.; MAGENTA, M. Governo federal financia entidades para dependentes químicos denunciadas por maus-tratos e irregularidades. BBC Brasil, 17 jun. 2019. Disponível em: <https:// www.bbc.com/portuguese/brasil-48628172>. 
MARONNA, C. A. Nova lei de drogas: retrocesso travestido de avanço. Boletim IBCCRIM. São Paulo, v. 14, n. 167, p. 4, 2006.

MCALLISTER, W.B. Reflections on a century of International Drug Control. LSE Ideas: governing the global drug war, London, p. 17-24, Oct. 2012. (Special Report, SR014).

MILLS, J.H. Science, diplomacy and cannabis: the evidence base and the international drugs regulatory system 1924-1961. LSE Ideas: governing the global drug war, London, Oct. 2012. (Special Report, SR014).

PAIVA, L. G. M. Panorama internacional das políticas sobre drogas. Boletim de Análise Político-Institucional, n. 18, p. 99-106, 2018.

PESSOA, O. A. G; CUNHA, A. S. Efeitos da nova regulação uruguaia sobre cannabis na fronteira com o Brasil: observação sobre os sistemas brasileiros de saúde e segurança pública. In: SANTOS, M. P. G. (Org.). Comunidades terapêuticas: temas para reflexão. Brasília: Ipea, 2018.

PIRES, R. R. C.; SANTOS, M. P. G. Desafios do multiprofissionalismo na implementação da redução de danos nos centros de atenção psicossocial álcool e outras drogas. Revista Saúde e Sociedade, no prelo.

- Alternativas de cuidado a usuários de Drogas na América Latina: desafios e possibilidades de ação pública. Brasília: IPEA/CEPAL, 2021.

RODRIGUES, T. Tráfico, guerra, proibição. In: LABATE, B. C. et al. (Org.). Drogas e cultura: novas perspectivas. Salvador, UFBA, 2008. p. 91-103.

ROSSAL, M; CURBELO, M.; MARTINEZ, E. Usos y políticas del cannabis en la frontera Uruguay-Brasil: percepciones, moralidades y trayectorias de actores públicos y usuarios de cannabis en las ciudades de Artigas, Rivera, Rio Branco y Chuy. Brasília: Ipea, 2017. (Relatório de Pesquisa).

SANTOS, M. P. G. dos. Perfil das Comunidades Terapêuticas Brasileiras. Brasília: Ipea, 2017. (Nota Técnica, n. 21). Disponível em: <https://www.ipea.gov.br/portal/index.php?option=com_ content \&view=article\&id=29865\&Itemid=6>.

SANTOS, M. P. G. (Org.) Comunidades terapêuticas: temas para reflexão. Brasília, Ipea, 2018.

SANTOS, M. P. G.; PIRES, R. R. C. Sentidos da "redução de danos" nos CAPS AD do Distrito Federal: entre o "escopo ampliado" e traduçôes conservadoras. Teoria e Cultura, v. 15, n. 2, 2020a. (Dossiê Drogas: novas abordagens e novos desafios acadêmicos e sociais). Disponível em: <https:// periodicos.uff.br/index.php/TeoriaeCultura/issue/view/1504>.

Antagonismo cooperativo na provisão de cuidado a usuários de drogas no Distrito Federal: conflitos e parcerias entre CAPS AD e CTs. Brasília: Ipea, 2020b. (Texto para Discussão, n. 2604). Disponível em: <https://www.ipea.gov.br/portal/index.php?option=com_ content \&view=article $\&$ id $=36927 \&$ Itemid $=448>$.

SCURO, J. Monitoreo y evaluación de los efectos de la nueva política uruguaya de regulación del mercado de cannabis sobre la seguridad en la zona de frontera: percepción de los agentes de seguridade y actores del sistema de justicia criminal uruguayos. Brasília: Ipea, 2017. (Relatório de Pesquisa). 
SOARES, M. K. Ignorância e políticas públicas: a regulação de cannabis medicinal no Brasil Boletim de Análise Político-Institucional, n. 24, 2020.

THOUMI, F.E. Re-examining the 'medical and scientific' basis for interpreting the drug treaties: does the 'regime' have any clothes? LSE Ideas: after the drug wars: report of the LSE Expert Group on the Economics of Drug Policy, pp. 19-29, 2016. Disponível em: <https:/www.lse.ac.uk/ideas/ Assets/Documents/reports/LSE-IDEAS-After-Drug-Wars.pdf>. 